NIST

PUBLICATIONS

\section{PHYSICS, CHEMISTRY AND ENGINEERING IN THE 1990'S}

\section{Helmut Hellwig}

U.S. DEPARTMENT OF COMMERCE Natlonal Instltute of Standards and Technology

Galthersburg, MD 20899
U.S. DEPARTMENT OF COMMERCE Robert A. Mosbacher, Secretary NATIONAL INSTITUTE OF STANDARDS AND TECHNOLOGY

John W. Lyons, Director 
NATTONAL INSTTTUTE OF STANDARDS \&

TECHNOLOGY

Research Information Center

Gait?ersburg, MD 20899

\section{DATE DUE}

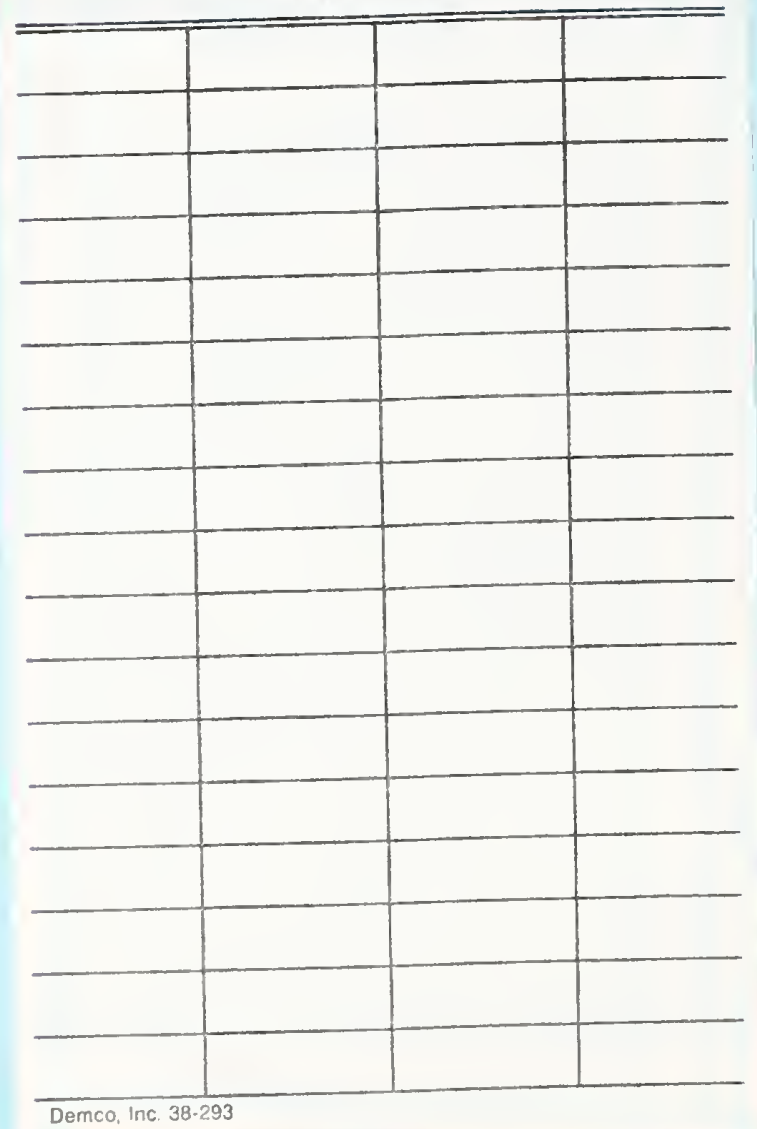




\section{PHYSICS, CHEMISTRY AND ENGINEERING IN THE 1990'S}

\section{Helmut Hellwig}

U.S. DEPARTMENT OF COMMERCE National Institute of Standards and Tochnology

Calthersburg, MD 20899

Aprll 1990

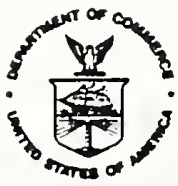

U.S. DEPARTMENT OF COMMERCE Robert A. Mosbacher, Secretary NATIONAL INSTITUTE OF STANDARDS AND TECHNOLOGY

John W. lyons, Director 


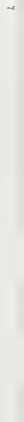


SUMMARY AND INTRODUCTION

THE SURVEYS OF THE NATIONAL RESEARCH COUNCIL (NRC)

Physics and Chemistry surveys

Engineering Surveys

SUMMARY OF OBSERVATIONS

Observations of the Brinkman Survey (Physics)

Observations of the Pimentel survey (Chemistry)

Joint observations of the Brinkman and Pimentel surveys

Joint observations of the Puckett and Amundson Surveys

APPLICATIONS AND PRIORITY AREAS FOR RESEARCH

Applications of National Interest

Priority Areas for Research

\section{REFERENCES}

APPENDIX A - DETAILED RATIONALE FOR NEW DISCIPLINES

Surface science

"Geo"

Fluids

"Bio"

APPENDIX B - APPLICATIONS OF NATIONAL INTEREST IN THE FIELD OF PHYSICS

Biological Physics

Materials Science

Physics-Chemistry Interface

Geophysics

Computational Physics

Microelectronics

Optical Information Technologies

Instrumentation

Energy and Environmental Preservation

National Security

Medical Applications

APPENDIX C - APPLICATIONS OF NATIONAL INTEREST IN THE FIELD OF CHEMISTRY

New Processes

More Energy

New Products and Materials

More Food

Better Health

Biotechnologies

Better Environment

Continued Economic Competitiveness

Increased National Security

APPENDIX D - PRIORITY RECOMMENDATIONS MADE BY SURVEYS OF THE NRC

Pimentel survey

Amundson Survey

puckett Survey

Brinkman Survey 

SUMMARY AND INTRODUCTION

During the past several years, the National Research Council (NRC)

commissioned and published four surveys (Reference 1 through 4 ) which are directly relevant to physical, chemical and engineering research. The objective of this report is not only to summarize the considerable complexity of these surveys, but it is also hoped that this report may facilitate the planning of research at the National Institute of Standards and Technology [NIST, formerly the National Bureau of Standards (NBS)].

The four surveys, their structure, concept and content are introduced and observations common to all four surveys are reported. Common observations include those on interdisciplinary linkages, "new disciplines", the continuum of science and engineering, and the importance of instrumentation. The areas of application and the research opportunities in physics, chemistry and engineering, as seen by the respective surveys, are summarized. The report concludes with a listing of priority areas for research as recommended by the four NRC surveys.

1 


\section{Physics and Chemistry Surveys}

The Brinkman (1) and Pimentel (2) Surveys were commissioned by the National Research Council (NRC) to provide an overview of the disciplines of physics and chemistry and to relate results, activities and opportunities to national objectives and policies.

The chemistry survey was produced by 26 panel members organized into five task forces. The chemistry survey, with a total of 344 pages, is a coherent document with a high degree of integration and similarity of structure in the different subject areas. The survey recognized three technical/scientific subgroups:

$$
\begin{aligned}
& \text { 1. Control of Chemical Reactions } \\
& \text { 2. Dealing with Molecular Complexity } \\
& \text { 3. Chemistry and National Well-Being }
\end{aligned}
$$

In addition, there are chapters on "manpower and education" and "resources for basic research" in the chemical sciences. Each of the three technical subgroups features chapters on "intellectual frontiers" and "instrumentation"; beyond this, they are structured according to applications/target areas, such as energy, health, and environment. As a result, we have a coherent treatment of basic research, results, applications, future scientific opportunities, and likely economic benefits. However, there is a high degree of overlap between the different scientific and technical subject areas.

The physics survey is based on contributions from eighty panel members organized into seven independent panels. The physics survey features eight volumes and a total page count of 1,869. One of the volumes is an overview and summary, the other seven are the independent work of the panels as follows:

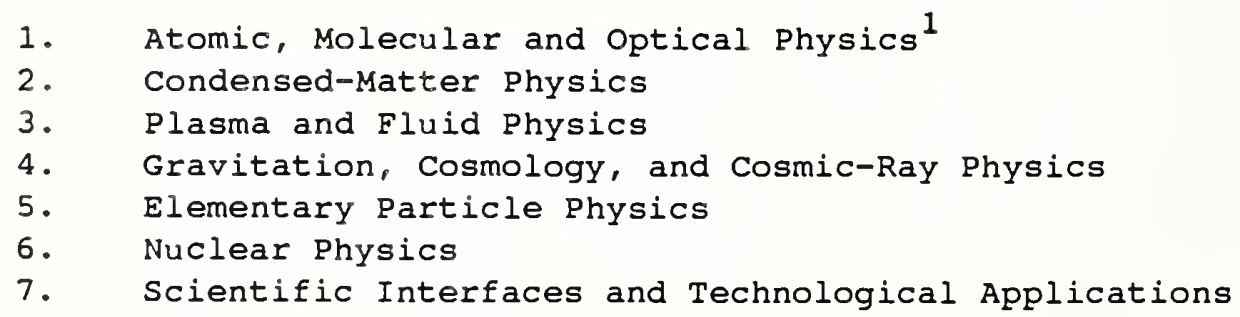

These seven volumes are different in their approaches to their respective subject areas. Some deal with applications and economic benefits explicitly, others only implicitly. As a result, it is not easy to extract general

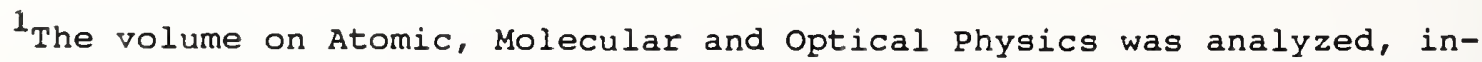
depth, by the NBS Discussion Group on Atomic Physics, Richard D. Deslattes (Chairman) who issued, on December 6, 1985, a report entitled "Atomic Physics at NBS". 
conclusions, and there are no priorities given between the different subject areas; however, technical overlap is minimal.

\section{Engineering Surveys}

Following the publication of the Brinkman and Pimentel Surveys, the National Research Council issued two engineering surveys. It appears appropriate to view the Puckett survey (3) as the engineering complement to the Brinkman Survey; the Amundson Survey (4) explicitly refers to the Pimentel survey as being a complementary document. Naturally, this is an oversimplification and, indeed, there is considerable overlap between the two engineering surveys in the area of materials and bioengineering and some overlap in many other areas.

The Puckett Survey was performed using seven individual panels as follows:

1. Bioengineering Systems Research

2. Construction and Structural Design Systems Research

3. Energy, Mineral and Environmental Research

4. Information/Communications/Computation/Control systerns Research

5. Manufacturing Systems Research

6. Materials Systems Research

7. Transportation Systems Research

The Puckett Survey features the original reports of these seven panels and integrates them in a coherent fashion, including prioritization of the individual recommendations of the seven panels. The survey identifies and discusses 14 priority areas for engineering research.

The Amundson Survey was performed by seven subpanels as follows:

1. Biochemical and Biomedical Engineering

2. Electronic, Photonic and Recording Materials and Devices

3. Advanced Materials

4. Energy and Natural Resource Processing

5. Environmental Protection Safety and Hazardous Materials

6. Computer-Assisted Process and Control Engineering

7. Surface and Interfacial Engineering

The Survey integrates the input of the seven panels into joint recommendations for eight areas of priority research in chemical engineering. 


\section{SUMMARY OF OBSERVATIONS}

\section{Observations of the Brinkman Survey (Physics)}

Support for physics is motivated by:

1. Strategic national goals

2. Pride of scientific leadership

3. Societal impact through symbiosis with other natural sciences, and stimulus of advanced technology

Physics impacts the society and the economy through its interfaces with other natural sciences, and through application to technology, medicine, and national defense. New scientific disciplines arise from strong interfaces such as those with biology, geology and materials science. Traditional interfaces with chemistry and mathematics promise a revolution in the way research is conducted. Interdisciplinary science is one of the most exciting promises for the coming decade.

Physics activity has become a continuum from the most basic research to engineering applications. The continuum thus created, speeds technology transfer and innovation. Continued technological progress depends on intense interaction between physics and engineering just as continued scientific progress depends on interaction between physics and other sciences. In those areas of technology, where new physical science is moving rapidly into application there is no point in attempting to distinguish between physics and engineering. In this context, contributions to microelectronics, optical communications, new instrumentation, medical diagnosis and treatment, national defense, energy, and environmental solutions are particularly highlighted.

\section{Observations of the Pimentel survey (Chemistry)}

Chemistry impacts the society and the economy significantly: U.S. chemicals feature nearly $\$ 200$ billion in sales; chemistry is the key to improvement of existing processes, the introduction of new ones, and advances in chemical catalysis and synthesis. Ninety-two percent of our energy consumption relates to chemical technology; better control of chemical reactivity is needed to reduce cost and protect the environment. New materials are based on interdisciplinary research that includes chemistry. Novel approaches to food preservation and to food production through soil conservation, and photosynthesis in combination with other disciplines require clarification of the chemistry of biological life cycles. Important contributions to medicine are possible through rational drug design and synthesis of new compounds. Genetic engineering has been built upon basic chemical principles that determine the chemical structure and functional relationships between molecules and supermolecules (proteins, DNA) within biological systems. Chemistry is now poised to clarify the complex biological processes of the life cycle at the molecular level. Safeguarding our environment requires that we know what's there, where it came from and what we can do about it. Chemistry can provide analytical techniques and alternatives in products and 
processes. Chemistry contributes to national security in many areas including propulsion, weapons materials, munitions, corrosion protection, advanced strategic concepts such as stealth, detection, surveillance and countermeasures.

The socio-economic importance of chemistry is reflected in the fact that about twice as many chemists obtain Ph.D's as compared to physicists and by the fact that the total industrial employment in chemistry exceeds that of engineers which by itself is more than triple the employment of physicists.

\section{Joint Observations of the Brinkman and Pimentel Surveys}

\section{The Continuum of Science and its Applications}

There is a strong theme of viewing science and its applications as a continuum. Both Surveys do not make distinctions between engineering and science, nor are there strong differentiations between research, development, and practical applications. As stated earlier in this report, the Pimentel Survey recognizes that it does not explicitly deal with chemical engineering; nevertheless, chemical engineering is an integral theme in the Pimentel Survey. In the Brinkman Survey, strong statements are made about viewing physics (in particular, atomic, molecular and optical (AMO) and condensedmatter physics) and electronics engineering as a continuum. "Continuum" here relates to all of the following: use of human talent, use and application of investigative tools and instruments, and the increasing parallelism of technical progress in science and application (in contrast to the traditional, sequential progression from basic science to engineering applications).

\section{The Role of Instrumentation}

Both Surveys aggregate activities, report results, and project future developments in terms of kind and specificity of investigative tools such as instruments and facilities. The foregoing would be a trivial statement if we only talked about elementary particles, nuclear physics, or analytical chemistry. However, this approach is evident in all other areas; e.g., in condensed-matter physics, investigative tools are even used as one of three topical areas to break down this field of physics. In the Pimentel survey, instrumentation plays the role of a cross-cutting matrix of the subject areas of the survey. Thus, we may speculate:

- Is physics (or least a good portion of it) assuming the role of "toolmaker"?

- Is chemistry, correspondingly, increasingly characterized by using the tools which physics provides?

Beyond this, the demarcation lines between chemistry and physics apparently have become blurred, since the principal topic of both disciplines has become the same: a focus on the complexity which lies between the micro and the macro, the atom and the macroscopic world; i.e., the analysis and understanding of multi-atom complexities, interactions, and interfaces using sophisticated instruments. 
Both Surveys have overlapping coverage in a number of areas. Four of these areas stand out as having substantial applications potential and economic leverage as well as capacity for incubating new-disciplines, analogous to those which created materials science many years ago:

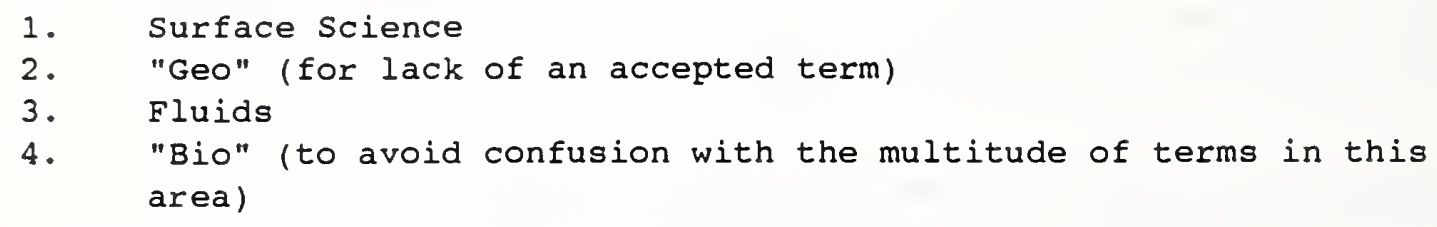

These four areas share the following features:
1. They are highly interdisciplinary, especially as regards traditional physics and chemistry.
2. They have a sweeping range of applications.
3. There is a high degree of immediacy; new knowledge can rapidly reach application.

Details about all four areas (or "new disciplines") are provided in Appendix A.

\section{Joint Observations of the Puckett and Amundson Surveys}

\section{The Definition of Engineering Research}

Both Surveys are emphatic in not perceiving engineering research as the activity which follows scientific research. They distinguish engineering research from scientific research by the motivator for the activities.

Engineering research is motivated, primarily, by the prospect for gaining new knowledge about the man-made world (scientific research deals with the natural world). The man-made world is perceived as both the world of today and the projected world of tomorrow. There is an emphasis on explicit societal demands; in other words, engineering research is market-oriented with the market encompassing product and process opportunities, environmental issues, health and safety, etc.

\section{Linkage to Science Research}

Both Surveys strongly refuse to have a boundary towards the fundamental side of scientific inquiry. They claim that, if needed, advances on the fundamental side must be made by engineering research, and that there is no limit to the legitimacy of inquiry at the most fundamental atomic, molecular or quantum levels. It is interesting to note that this parallels the claim of the Brinkman and Pimentel Survey (especially the Pimentel survey) to reach all the way into applications. Equally, the engineering researchers seem to be worried about being disenfranchised from the scientific foundations of their 
the way into applications. Equally, the engineering researchers seem to be worried about being disenfranchised from the scientific foundations of their research; similiarly, the physical and chemical scientists are worried about being disenfranchised from applications.

\section{Interdisciplinary Research}

Both engineering surveys are very emphatic about the need for interdisciplinary research. They use the term interdisciplinary in two dimensions: one is the cross-cutting to their science partners in physics and chemistry; the other dimension is that of the traditional academic disciplines, such as electronics and civil engineering. In fact, the puckett Survey is consciously and deliberately aggregated around what the survey calls "systems", and the statement is made that engineering "systems" research in all areas of economic and technological importance cuts across established disciplinary boundaries. It is noted that industry has already operated for some time in a cross-disciplinary "systems" mode.

\section{Process and Processing}

Both engineering surveys are conscious of the importance that engineering research has in process design and process technology, because of the engineering shift from focus on product to focus on process. The principal impact of this is seen in such areas as biomaterials, materials processing, microelectronics, information storage technology, and biomass production. It may be said that both surveys view the essence of engineering research as being involved in designing processes, in order to allow the new technologies to be brought to market and become major economic forces.

\section{Systems Integration}

Both engineering surveys emphasize that one of the most significant changes for the present and future is the ability to integrate large systems. This is perceived partly as resulting from the application of computer technology (ranging from expert systems to supercomputers), and also partly due to the increasing amount of knowledge and data required for both natural and manmade subsystems in combination with our ability to establish interdisciplinary links. Integration of systems, including both products and processes, may be the most fundamental change in the approach to manufacturing since the invention of work breakdown (assembly line) early in this century. "Product and process integration" is understood in a very broad sense: it includes diverse, large scale systems such as those for materials synthesis and materials processing. It eliminates the need for process and product prototypes by using computer-simulation. Another example is the integration of vehicle design with communication control subsystems in air or surface transportation. 
Beyond specific recommendations regarding facilities, funding, manpower and education, all surveys emphasize the intent of their disciplines to make contributions towards the long-term health of the U.S. economy and the U.S. technology enterprise. The recommendations are intended to improve the effectiveness of physical, chemical and engineering research, and to focus and increase their applications potential.

In this report, these views, recommendations and priorities are reported as they are presented in the respective NRC Surveys.

\section{Applications of National Interest}

The two following lists summarize the view of the Brinkman and Pimentel Surveys, respectively, regarding the primary impact areas of the research undertaken. Each of these areas is detailed in Appendix B (Physics) and Appendix C (Chemistry).

As viewed by physics:

- Biological Physics

$\circ$

$\circ$

$\circ$

$\circ$

$\circ$

As viewed by chemistry:

- New Processes

- More Energy

- New Products \&

Materials

- More Food

- Better Health

Microelectronics $\circ$

o

$\circ$

$\circ$

$\circ$

Medical Applications

Optical Information Technologies

Instrumentation

Energy \& Environmental

Preservation

National Security $\circ$

$\circ$

$\circ$

$\circ$
Biotechnologies

Better Environment

Continued Economic Competitiveness

Increased National security 
Three of the four Surveys recommend that priority be given to selected areas of research. The exception is the Brinkman Survey in which no selection of priorities is discernable. In the following three subchapters, the priorities of the Pimentel, Puckett, and Amundson Surveys are summarized together with the respective rationale used in the prioritization. A more detailed explanation of each of the priority areas may be found in Appendix D.

\section{Pimentel Survey}

Rationale: Balance between industry (current importance), academia (new avenues for tomorrow), and mission agencies.

\section{Priority Areas:}

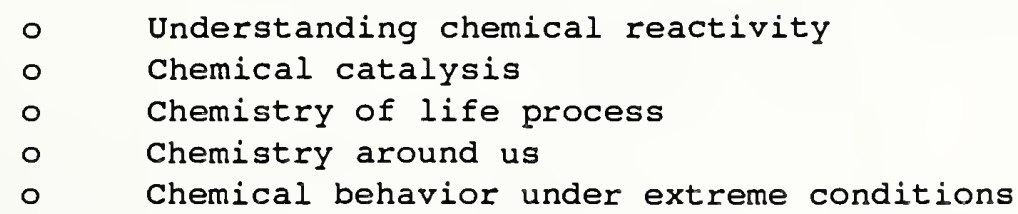

\section{Puckett Survey}

Rationale: Existence of technological opportunity based on recent advances in science or engineering. Strong potential to improve industrial

competitiveness, quality of life, or national security of the United States.

\section{Priority Areas:}

Three of the 14 research areas were assigned extremely high priority; they lead the list as its first three entries:

$\begin{array}{ll}\circ & \text { Complex system software } \\ \circ & \text { Advanced engineered materials } \\ & \text { Manufacturing systems integration } \\ \circ & \text { Bioreactors } \\ \circ & \text { Construction robotics } \\ \circ & \text { Vehicle/guideway system integration } \\ \circ & \text { Alternative fuel sources } \\ \circ & \text { Low grade mineral recovery } \\ \circ & \text { Biomedical engineering } \\ \circ & \text { Hazardous material control } \\ \circ & \text { Mechanics of slowly deteriorating systems } \\ \circ & \text { Computer-aided design of structures } \\ \circ & \text { Manufacturing modeling and simulation } \\ \circ & \text { Electronic device and packaging technology }\end{array}$


Amundson Survey

Rationale: Starting New Technologies; Maintaining Leadership in Established Technologies; Protecting and Improving the Environment; Developing Systematic Knowledge and Generic Tools.

\section{Priority Areas:}

- Biotechnology and biomedicine

- Electronic, photonic and recording materials and devices

- Microstructured materials

- In situ processing of energy and mineral resources

- Iiquid fuels for the future

- Responsible management of hazardous substances

- Advanced computational methods and process control

- Surface and interfacial engineering 
(1) "Physics through the 1990's; Physics Survey Committee, William F. Brinkman (Chairman); National Academy Press, Washington, DC, 1986.

(2) "Opportunities in Chemistry"; Committee to Survey Opportunities in the Chemical Sciences, George C. Pimentel (Chairman); National Academy Press, Washington, DC, 1985.

(3) "Directions in Engineering Research; an Assessment of Opportunities and Needs," Engineering Research Board, A.E. Puckett (Chairman); National Academy Press, Washington, DC, 1987.

(4) "Frontiers in Chemical Engineering; Research Needs and Opportunities," Committee on Chemical Engineering Frontiers, N.R. Amundson (Chairman); National Academy Press, Washington, DC 1988.

\section{ACKNOWLEDGEMENTS}

The author wishes to thank Dr. Judah Levine and Dr. Arthur O. Mccoubrey for their helpful comments and suggestions, and Mrs. Pamela Reppert and Mrs. Toni Nashwinter for their editorial contributions and logistics support. 
APPENDIX A

DETAILED RATIONALE FOR NEW DISCIPLINES 


\section{Surface science}

\section{Background}

Both Surveys give considerable coverage to the subject of surface science and its applications. The principal coverage in the physics survey is in

condensed-matter physics with contributions from AMO physics; it is also addressed in the survey on scientific interfaces and technological applications. The chemistry survey features surface science and applications in the chapter on new processes and the chapter on national well-being; in particular, it is discussed under instrumentation. In their approach to, and coverage of, surface science, both the Brinkman and Pimentel Surveys have considerable similarity. They essentially deal with three areas: investigative tools, science frontiers, and applications.

\section{Investigative Tools}

Investigative tools include all aspects of microscopy, the use of particle beam probes (electrons, atoms, molecules), and nearly all forms of radiations from infrared through optical to $x$-rays and neutrons. It has proven to be difficult to determine surface properties unambiguously from single sets of data. Consequently, several methods are often used to study a single object. The following table combines information obtained from both the physics and chemistry surveys.

The codes that are used in the table have the following meaning:

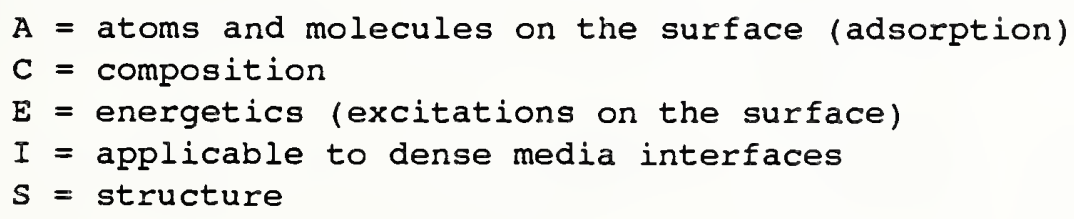




\begin{tabular}{|c|c|c|c|c|}
\hline Surface Analysis & Acronym & $\begin{array}{c}\text { Phystcal } \\
\text { Measurements }\end{array}$ & Physical Basis & $\begin{array}{l}\text { Property } \\
\text { Studied }\end{array}$ \\
\hline Auger spectroscopy & AẼs, Auger & $\begin{array}{l}\text { Electrons. } \\
2-3 \mathrm{keV} \\
X-\text { rays }\end{array}$ & $\begin{array}{l}\text { Electron emision from } \\
\text { excited surface atoms }\end{array}$ & $\mathrm{C}$ \\
\hline Brillouin scattering & --- & $\begin{array}{l}\text { Infrared } \\
\text { light }\end{array}$ & $\begin{array}{l}\text { Scattering of light from } \\
\text { surface plionons }\end{array}$ & E. I \\
\hline $\begin{array}{l}\text { Electron energy loss } \\
\text { spectroscopy }\end{array}$ & EELS & $\begin{array}{l}\text { Electrons. } \\
i-10 \mathrm{eV}\end{array}$ & $\begin{array}{l}\text { Vibrational excitation of } \\
\text { surface molecules by } \\
\text { inelastic reflection }\end{array}$ & A, E, S \\
\hline $\begin{array}{l}\text { Extended X-ray } \\
\text { absorption fine } \\
\text { structure }\end{array}$ & EXAFS & $X$-rays & $\begin{array}{l}\text { Interference effects in } \\
\text { photoemitted electron }\end{array}$ & A.S \\
\hline Fleld ion microscopy & -- & Ions & $\begin{array}{l}\text { Atoms are ionized } \\
\text { by the electric } \\
\text { field near a sharp } \\
\text { tip }\end{array}$ & C.S \\
\hline Infrared spectroscopy & IRS & $\begin{array}{l}\text { Infrered } \\
\text { IIght }\end{array}$ & $\begin{array}{l}\text { Vibrational excitation by } \\
\text { absorption }\end{array}$ & A.B.I \\
\hline Ion scattering & ISS & $\begin{array}{l}\text { Inert gas } \\
\text { lons }\end{array}$ & Blast1c scattering & $\mathrm{C}, \mathrm{S}$ \\
\hline Ion sputtering & -- & $\begin{array}{l}\text { Inert gas } \\
\text { lons }\end{array}$ & $\begin{array}{l}\text { Surface atom efection by } \\
\text { lon bombardment }\end{array}$ & C.S \\
\hline $\begin{array}{l}\text { Laser-Induced second } \\
\text { harmonic generation }\end{array}$ & $\infty-$ & $\begin{array}{l}\text { V1sible \& UV } \\
\text { light }\end{array}$ & $\begin{array}{l}\text { Non-1Lnear effects in high- } \\
\text { photon fleld }\end{array}$ & A.I \\
\hline $\begin{array}{l}\text { Laser microprobe mass } \\
\text { spectrometry }\end{array}$ & -- & $\begin{array}{l}\text { V1sible \& UV } \\
\text { light }\end{array}$ & $\begin{array}{l}\text { Pocused 11ght-1nduced } \\
\text { molecular desorpt1on }\end{array}$ & $A, C$ \\
\hline $\begin{array}{l}\text { Low energy electron } \\
\text { diffrection }\end{array}$ & LERD & $\begin{array}{l}\text { Electrons. } \\
10-300 \mathrm{eV}\end{array}$ & $\begin{array}{l}\text { Elastic beck scattering. } \\
\text { diffraction }\end{array}$ & A.S \\
\hline $\begin{array}{l}\text { Molecular beam } \\
\text { scattering }\end{array}$ & $-\infty$ & $\begin{array}{l}\text { Holecules of } \\
\text { known energy }\end{array}$ & $\begin{array}{l}\text { Inelastic reflection off } \\
\text { surface }\end{array}$ & $A, E$ \\
\hline Neutron scatter Ing & -- & $\begin{array}{l}\text { Thermal (or } \\
\text { belou) } \\
\text { neutrons }\end{array}$ & $\begin{array}{l}\text { Glancing incidence neitron } \\
\text { spectroscopy }\end{array}$ & A.E.S \\
\hline $\begin{array}{l}\text { Photoelectron } \\
\text { spectroscopy }\end{array}$ & $\begin{array}{l}\text { XPS. UPS. } \\
\text { ESCA }\end{array}$ & $\begin{array}{l}\text { X-rays, UV } \\
\text { (synchrotron) }\end{array}$ & $\begin{array}{l}\text { Blectron emission fror } \\
\text { Inner shells }\end{array}$ & A.C.S \\
\hline Raman & Rnman & V1stble 11ght & $\begin{array}{l}\text { Raman scattering, resonant, } \\
\text { surface-enhanced }\end{array}$ & A.I.S \\
\hline $\begin{array}{l}\text { Scanning electron } \\
\text { microscopy }\end{array}$ & SEM & Electrons & Electron scattering & s \\
\hline $\begin{array}{l}\text { Secondary Ion mass } \\
\text { spectroscopy }\end{array}$ & SIMS & $\begin{array}{l}\text { Ions, } \\
1-20 \mathrm{keV}\end{array}$ & $\begin{array}{l}\text { Ion beam-1nduced ejection } \\
\text { of surfece atoms as lons }\end{array}$ & C \\
\hline $\begin{array}{l}\text { Spin polarized } \\
\text { electron microscopy }\end{array}$ & -- & $\begin{array}{l}\text { Polarized } \\
\text { electrons }\end{array}$ & $\begin{array}{l}\text { Electron sattering } \\
\text { dependent on surfece } \\
\text { magnetization }\end{array}$ & $\mathbf{E}$ \\
\hline Thermal desorption & TDS & Heet & $\begin{array}{l}\text { Thermally-tnduced } \\
\text { desorption, decomposition } \\
\text { of adsorbates }\end{array}$ & A. E \\
\hline Tunnelling microscopy & --- & Electrons & $\begin{array}{l}\text { Strong dependence of } \\
\text { electron current across gap } \\
\text { between surface and probe }\end{array}$ & I \\
\hline
\end{tabular}


In bulk crystal (without defects) the structure provides that for each interior atom chemical bonding of neighboring atoms takes place in all three dimensions. At a clean surface, however, the atoms have unsatisfied bonding capacity because neighboring atoms are missing. As a result, the important scientific frontiers involve structure and excitations at the surface. of interest is the behavior, excitation and interaction of one or more species of adsorbed molecules. In particular, the time evolution of such interactions can be studied as the resolving power has reached below the picosecond level. Finally, there is a need to study the interfaces between solid surfaces and dense media including gases, liquids, and even other solids. Furthermore, surface manipulation is possible through deposition of atoms and molecules generating the possibility of surface structures with novel properties.

\section{Applications}

Applications include wear and corrosion, catalysts, optical and magnetic data storage, high-Tc superconductors, and large-scale circuit integration. Catalysts generate billions of dollars in annual revenue in the chemical processing industry. Regarding surfaces, we are concerned with heterogeneous catalysts, where a large surface area permits a chemical reaction to occur at a high rate and with specific selectivity. Both of these qualities relate to surface structure as well as to composition and energetics of the surface. Heterogeneous catalysts include molecular synthesis, metal catalysts, substitutes for precious metal catalysts, new catalysts to allow conversion of atmospheric nitrogen to nitrates (nitrogen fixation), biomass conversion to utilize hydrocarbons, to convert methane to methanol, etc. Also needed are catalysts to remove contaminants from air and water.

The understanding of corrosion leads to corrosion protection and, in general, reduction of wear. Again, the means to do this relate to the understanding and control of structures, energetics, and adsorbed substances. The understanding of surface structure at the semiconductor-oxide interface, of the topology of surfaces, and more recently, the manipulation of surfaces and the creation of surface layers is important to very large scale integration of electronic circuitry. Optical and magnetic data storage also benefit from better understanding, especially in connection with reliability; i.e., long term performance of the medium in benign as well as demanding environments.

Very close relationships exist between surface science and materials science. In fact, they are complementary activities with an increasing interdependence, especially when one considers that materials science cannot ignore corrosion and wear and, more recently, materials science needs in-depth understanding of surface properties in the area of composite materials. In this case, the properties of surfaces of the re-enforcing fibers are of overriding importance in connection with the strength and durability of the composites. 
Originally, "Geo" has been viewed as a subfield of geology. In the past, individual scientists were "converted" from other disciplines to contribute to geology, and methodologies were adopted from other sciences. More recently, it has been characterized by collaborative, interdisciplinary research. "Geo" has begun to assume an interdisciplinary, new focus as physics and chemistry have begun to deal with very complex scenarios, such as disordered systems, non-linear dynamics, turbulence and chaos, and large scale fluid dynamics. In addition, measurement technology has reached new refinement levels. This includes probing and imaging from space using radiation throughout the electromagnetic spectrum, measurements of position and distance with millimeter precision based on modern satellite navigation systems, and various forms of laser ranging and long baseline interferometry. Advances in remote sensing combined with data collection and data processing have revolutionized data gathering from the atmosphere, the oceans, and from below ground.

Advances in geochemistry have been based on laboratory capabilities at high pressures and high temperatures as well as on substantially more refined analytical techniques. This has allowed the study of geochemical cycles, i.e. the understanding of the changing chemical and physical environment of a given element during long term processes of crystallization, dissolution, metamorphosis, and weathering. The field of organic geochemistry has been revitalized especially in relation to stability conformation and decomposition of organic molecules with relevance to coal, oil and organic deposits.

Geo-phenomena involve, on a large scale, solids, liquids and gases, radiation and matter, and human society and the environment. The earth is not just an environment; it has become an interactive laboratory, on a global scale, with man-made modifications occurring from within and natural changes from outside the planet. The phenomena which are observable have risen to national and international importance. Relationships exist to national security, to environmental protection, to the generation of sources of energy as well as to the disposition of energy and waste products.

\section{The Concept of Geo-Control}

Elements of Geo-Control include the prediction, forecasting and modification of weather, of ocean currents, of tectonic motion, of earthquakes, as well as waste disposal, and energy management. Specific concerns are well known to everyone but they still need much improved understanding and, ultimately, control of the ozone layer, acid rain, and climatic change. Solutions require contributions from many disciplines; they lie at the interface between the micro scale and macro level. 


\section{Fluids}

\section{Definition of Fluids}

The physicists view fluids as part of condensed matter physics and also as a discipline by itself. The chemists, similarly, view fluids as part of condensed-phase chemistry; it is also perceived as a substantial crosscutting topic with importance to separations, to analytical chemistry and to catalysts. Three-dimensional treatment leads to the proper understanding because many important effects never appear in two dimensions. Real fluid flow usually involves complicated geometries and topologies, multiphase flows, thin boundaries and internal layers, interacting shocks, nonlinear instabilities, and interfaces with other materials. All this is further complicated by chemical reaction, magneto-hydrodynamic effects, radiation, etc. Application areas involving transition to turbulence, and turbulence itself, include flow in pipes, thermal convection, and boundary-layer phenomena. Applications relating to shocks range from laser fusion to sonic boom propagation. Computational fluid mechanics and dynamics influence the design of almost any object within a fluid flow ranging from automobiles, ships, and undersea vehicles to their components such as internal combustion engines and rocket motors.

The experimental techniques for studying fluid dynamics can be divided into two categories: probing single-particle dynamics and collective (many-body) motions. Tools for study include NMR/ESR, infrared and Raman spectroscopy, picosecond laser spectroscopy, dielectric relaxation, ultrasound, acoustic birefringence, and neutron scattering. Of additional interest are colloidal systems where microscopic structure and interactions are not very well understood. Also, the liquid crystal form of organization and asymmetry has substantial potential for major new developments, especially in the area of memory display and high speed updating of displays. Liquid crystals can be based not only on small organic molecules, but also on amphophilic systems, polymers, and colloidal suspensions. Fluid physics addresses problems such as transport across biological membranes, the appearance of solitary waves, planetary atmospheres, the efficiency of flight (animals as well as airplanes), the process of combustion and heat transfer (relating to the effectiveness of engines), increasing the efficiency in gas turbines, and, most importantly, the efficiency of chemical processing systems.

\section{Science Frontiers}

The scientific specialties embodied in fluids are described by a number of terms, such as fluid mechanics, fluid physics, gas dynamics, liquids, biofluid mechanics, liquid state dynamics, and many more. Intellectual frontiers include: - advancement in the understanding of the origins of turbulence, - the development of chaos, - flow prediction and control of turbulent flows, - understanding of three-dimensional, compressible viscous flows, - real-time multipoint measurement of flow fields (using lasers),

- interaction between chemical kinetics and fluid instabilities,

- multiphase flow systems, - reacting flows, • interaction with particulate systems and flow through porous media, • biofluids and its dynamics 
(including osmosis, cellular transport). Among the newer experimental approaches, relaxation techniques have proven to be powerful. Non-linear laser spectroscopy provides information about phenomena of trapping and solvation and, in general, the energy exchange between a solute molecule and its solvent environment. Of great interest is the study of how bulk phase transition properties emerge from liquid-solid phase transitions in small clusters, as the cluster size increases. Molecular dynamics allows the simulation and tracking of the time evolution of larger numbers of molecules. This is of importance to model properties of water and proteins in water as well as chemical reactions, molecular motion and energy transfer, interactions at the boundaries, phase transitions, glasses, etc.

\section{Importance to Chemical Engineering}

A significant share of outr economy is built around the chemical industry. Chemical synthesis and liquids under high pressure, therefore, deserve special mention. High pressure studies reveal the volume profile of the reaction and information of reaction pathways. Fluid behavior under critical conditions is of great importance to many practical applications. Surfaces and interfaces of near-critical fluids and fluid mixtures exhibit transitions and critical phenomena. Supercritical extraction is now used in research applications and, commercially, in preparation of many products. This is due to dramatic changes in solvent power with very small changes in pressure and temperature near the critical point. Research in the separation sciences focuses strongly on studies of properties of the liquid state and, in particular, includes solvent cage re-orientation, interactions between solvent and solute, and the chemical behavior of fluids under extreme pressures and temperatures. Separation science supports the industrial use in the separation of biochemicals from living organisms, and the extraction of rare materials, such as platinum for catalysts and uranium for nuclear fuel. The efficiency and future development of the chemical industry is tied to developing improved energy and cost efficiency, which is related to the use of catalysts. Before the technological potentialities of any of the novel catalysts can be realized, a better understanding of the solid-liquid boundary must be developed.

\section{"Bio"}

\section{Definition of "Bio"}

"Bio" appears to be a challenge to both physicists and chemists. Biophysics is a narrow and insufficient term. It is used in the sense of applying physics and physical instrumentation to topics in biology. Thus, the Brinkman Survey touches on the bio-theme principally by pointing out the contributions of physics to "Bio". Biochemistry offers a more integrated viewpoint; however, "Bio" is approached primarily as an extension of organic chemistry.

Both Surveys imply that it is difficult to draw boundaries and to define interfaces with other disciplines. Terminology and overlapping meanings abound. They include, but are not limited to, biotechnology, bioengineering, 
biomedicine, bioprocessing, biosensing, biomass engineering, biochemical engineering, biomedical engineering, biocatalysts, bioseparations, and many more.

The first two of these terms are most relevant to us; biotechnology is perceived as all-encompassing, including pharmaceuticals, diagnostics, materials, sensors, specialty chemicals, commodity chemicals, agricultural chemicals, plants and seeds, improved animal breeds, feed and feed supplements, flavors, fragrances, etc.

Bioengineering is perceived as the extension of advances in biology by engineering knowledge towards development of devices for health care, advancement of understanding of living systems, and the scale up of processes leading to new products.

The Physics Survey focuses on applications of advanced physical

instrumentation to biological problems and, with it, the studies of molecular genetics, protein structure, reaction of receptors and membranes, and the understanding of neural networks, including the brain (here, theories of chaos and partially disordered systems are relevant). The chemistry survey focuses on enzymes as biological catalysts that are crucial for the synthesis of materials and products, for biomass conversion, and for protein syrithesis. Included are the underlying foundations of recombinant DNA technology and genetic engineering, and biomimetic chemistry (adaptation, stabilization, and generation of new enzymes). Other major challenges are photosynthesis, nitrogen fixation (which is fundamental to the generation of most biological substances), novel materials for repair and replacement of human parts, drug delivery, and the use of micro-organisms to produce products and break down pollutants. Also discussed, at length, is the complex area of plants and animals including control of life cycles, growth promotion and inhibition, and feeds and anti-feedants.

\section{Biomaterials}

Both Surveys refer to the genesis of materials science as a discipline. They view the evolving bio sciences as going through stages which are reminiscent of the early stages of materials science, when it was formed out of the basic disciplines of physics and chemistry. As a consequence, it appears possible to define a biomaterials focus. The objective would be the generation of organic matter using principles found in, or adapted from, living organisms. Included in this focus are not only the characterization of the properties of biomaterials, but also the fundamental physical and chemical principles underlying the workings and modifications of living organisms including recombinant DNA molecular structure, protein synthesis, actions of enzymes, biomimetics, disordered systems, catalysts and biomass conversion. In analogy to materials science, biomaterials would have a strong need for measurement, sensors and instrumentation without which the control of the bioprocess which generates biomaterials could not be envisioned.

Biopolymers probably deserve a special, near-term focus. They are not only the foundation of life, but also the means for generating materials. A vast 
and diverse knowledge of physical and chemical structure, dynamics and functions has accumulated. One may be able to efficiently predict the properties of biomaterials and to generate novel proteins. Biological macromolecules are distinguished from the standard solids or liquids of condensed matter by their size and the fact that they are linear polymers. They typically contain of the order of 10,000 atoms. They are characterized by cooperative, conformational fluctuations that provide for the essential functions. In fact, the cooperative action of biopolymers is apparently keyed to the molecular specificity of certain functions, and it is the most fundamental challenge for our understanding and efficient production of biomaterials. 
APPENDIX B

APPLICATIONS OF NATIONAL INTEREST IN THE FIELD OF PHYSICS 


\section{Biological Physics}

Physics can now begin to address fundamental biological science at both molecular and many-bodied organizational levels. Important areas are: - biopolymers (DNA and RNA), in terms of quantum mechanical calculations of structure and dynamics; - cell-physiology and neural biology in terms of ion currents through single-transmembrane molecular channels; - gene manipulation in terms of study and control of structure; - organization of the brain in terms of the physics of partially-ordered systems with implications to robotics and artificial intelligence.

Synchrotron radiation, $x$-ray and electron beam crystallography, Raman spectroscopy, magnetic resonance are all applied to the understanding of protein structure and enzymatic processes.

\section{Materials Science}

Materials science is a fusion of metallurgy, chemistry and ceramics engineering and it has a common boundary with condensed-matter physics. New materials and processes are of great importance in terms of analytical and physical methods for their characterization; ideas and tools come from plasma and atomic physics. Glasses and amorphous materials can be understood as partially-ordered, many-particle systems. Crystal growth instabilities can be explained by the dynamics of non-linear systems. In materials science, the development of techniques to control, modify and create materials with particular properties are the central goals. Major contributors are the theories of disordered materials. Artificially structured materials at the atomic level and new optical materials (including polymers) are made possible by the confluence of many fields of physics and other science.

\section{Physics-Chemistry Interface}

Special importance is given to the study of polymers and liquids, to photochemistry and to photochemical processing. Order-disorder transitions are being studied with colloidal crystals, micro emulsions and liquid crystals. Organic conductors of electricity can be manipulated in their molecular architecture to range from insulators through semiconductors to metals. Polymers are viewed in terms of charge transport and electric conductivity, as well as in terms of polymer physics, including chain formation, molecular dynamics and surface properties. Dynamic behavior of exotic fluids formed by large complex molecules is studied down to femtoseconds; they include liquid crystals that exhibit, simultaneously, properties of fluids and solids. Catalysis is approached in terms of interactions between surfaces and chemical reactions taking place upon them, and in terms of the dynamics of the transient products of surface reactions. New strategies are developed for observation of molecular states in terms of unstable and excited molecular states using the spectacular sensitivity available from tunable lasers. 


\section{Geophysics}

Prediction of seismic activities, volcanoes, climatic changes and weather, as well as search for fossil fuels and the understanding of the environmental impact of energy production and consumptions, are all based on geophysics. Thus geophysics advances in terms of sophisticated measurement technology (mapping, very long baseline interferometry, seismology, magnetic and gravity measurements, etc.). Measurements of ocean floor rock magnetism and understanding of the thermodynamic driving forces associated with temperature gradients have brought about the most important recent development, the understanding of plate tectonics. Modern seismology and metrology based on lasers and time and frequency allow very precise monitoring of plate motions. In the atmosphere the understanding of turbulent fluid flow, together with large scale computing, advances weather prediction. However, the lack of a fundamental understanding of turbulence limits progress; similar limitations apply to the understanding of ocean currents.

\section{Computational Physics}

Computers have become a means for generating new theoretical discoveries. Elementary particle physics, quantum field theory, renormalization' theory, chemical kinetics, plasma simulation, etc., all depend on them. Chaos, associated with turbulent fluid flow, glasses, and ensembles of living cells, requires computational physics. In this area, interactive machine computation has become the research tool of choice and has made computational physics a subfield of science.

\section{Microelectronics}

Miniature lasers and photo detectors are based on solid state and materials physics. Optoelectronics, the combination of high electronic speed with nearly atomic-scale optical structures, requires support from high vacuum and surface physics. Very high speed switching and the development of a new energy technology is based on disordered or amorphous solids. Atomic scale insights into defects, dopants, and interfaces between different materials will determine the future of these atomic scale devices. An electronics technology industry exists which is capable of rapidly exploiting such advances. The information revolution is driven by the latest results in microelectronics and optical methods; together with the application of computers, this is revolutionizing communication and printing. Information processing, storage, signal detection, etc., may primarily benefit from advances in superconductivity. Advanced manufacturing with laser assistance and full use of robotics is spreading through every kind of industry.

\section{Optical Information Technologies}

Optical fiber communications systems depend on the combination of laser physics with research into the optical properties of materials and the understanding of absorption, fluorescence and scattering of light. In 
addition, the fundamental understanding, based on physical chemistry and kinetics, of the use of gas vapors is critical to manufacture ultrapure lightguide fibers. Very small lasers and photodetectors rely on an understanding of semiconductor physics combined with the ability to manipulate materials at the level of atomic layers or single atoms. Marriage of electronic and optical phenomena, including magneto-optic, electro-optic, and acousto-optic devices and optical bistability, make possible the vision of even faster, higher density and smaller electronics and memory devices.

\section{Instrumentation}

Medical instrumentation has grown explosively based on new ideas. These include: - the various tomographies; use of lasers (for manufacture, monitoring and control); - holography (for reading and reproduction of images, including labeling and pricing); - laser spectroscopy (for research, development, and manufacturing applications). Most importantly, manufacturing science has benefitted: the versatility of future manufacturing facilities resides in the hardware that permits a variety of measurements and changes of configuration. Specificity will reside in the software which determines the specific configuration of the product.

\section{Energy and Environmental Preservation}

Solar generation will become practical to the extent that near-atomic-scale materials processing becomes practical. Progress in photovoltaics is to be expected from a better understanding of microstructure as well as of surface effects. Nuclear fusion is propelled by superconductivity, laser and particle beam confinement, plasma and electromagnetic interaction phenomena, and particle-solid interaction effects. Combustion is still the most significant energy generation scheme. Research in the physics and the dynamics of combustion, measurement of combustion parameters, and physical chemistry aimed at the combustion process offer significant near-term returns. Better diagnostics of the combustion process are likely to make combustion more efficient. Environmental physics is concerned with the transport of matter and energy through the entire ecosystem. Dynamics, composition, and distribution of pollutants are characterized by neutron activation analysis and laser spectroscopy. Atmospheric concentration of carbon dioxide and particulates, created by fossil fuel burning, are important long-term problems and, as yet, inadequately understood. Data availability, analytical techniques, the understanding of turbulence in the atmosphere and in the oceans, and tectonic plate movements are critical for analyzing the future impact of emissions into the atmosphere of energy and particles.

\section{National security}

New means must be found to reduce detectability of military systems. In a corollary way, as the capabilities of concealment of weapons evolve, more effective detection systems will be required. They must be based on advanced signal processing methods and an understanding of the interaction of the 
various optical and electronic probes with materials. Success of directed energy weapons will rely on imaginative and currently unrealized applications of physics principles. Lasers are important for communication, guidance and surveillance. The prospect of intense, coherent radiation from the microwaves through the soft $x$-ray wavelengths has influenced detection technologies, identification technologies and, of course, countermeasures.

\section{Medical Applications}

A new era of analytical tools is beginning, including imaging techniques that combine physical investigative techniques with computer-assisted data reduction. Diagnosis has been revolutionized with computer-aided tomography (x-ray, ultrasonic, magnetic resonance). Surgery is beginning to rely on lasers; also, lasers begin to have the potential for analytical techniques in clinical biochemistry. However, optical techniques, including fiber optic and diagnostic instrumentation, are still in the infancy of their development. Continuous, accurate monitoring of crucial physiological parameters in realtime is possible based on the development of biosensors, and on new physical sensor techniques combined with miniaturized electronics, photonics and lowcost microprocessors. 
APPENDIX C

APPLICATIONS OF NATIONAL INTEREST IN THE FIELD OF CHEMISTRY 
New Processes

Heterogeneous Catalysis:

molecular sieve synthesis and catalysis; metal catalysis; substitutes for precious metal catalysis; conversion catalysts; catalysts to improve the quality of air and water.

Bomogeneous Catalysis:

activation of inert molecules; metal cluster chemistry; stereoselective catalysts.

Photocatalysis and Electrocatalysis:

photocatalysis; electrocatalysis; chemistry at the solid/liquid interface

Artificial-Enzyme Catalysis:

controlled molecular topography and designed catalysts; biomimetic enzymes.

\section{More Energy}

Petroleum:

recovery; refining; combustion.

\section{Natural Gas:}

low-molecular-weight hydro-carbons; clean-burning; catalytic-conversion.

\section{Coal:}

syn-gas conversion; organometallic chemistry; catalytic liquefaction.

\section{Shale oil \& Tar Sands:}

selective extraction; hydrogenation; selective absorption.

\section{Biomass :}

anerobic digestion; methane generation; reduction of carbon dioxide; energy production; genetically-engineered plants. 
Solar Energy:

photosynthesis; adenosine triphosphate; architecture of molecular chlorophyll; photoelectrochemistry.

\section{Nuclear Energy:}

geochemistry; highly automated remote-control reprocessing; leach-resistant matrices; corrosion chemistry.

\section{Fusion Energy:}

high temperature gradients; unipolar arcing; neutron damage; aggressive/surface interactions; coated refractories.

\section{New Products and Materials}

Plastics and Polymers:

polymers as structural materials; liquid crystals and polymer liquid crystals; block polymers and self-organized solids; photoresists and chemical etching.

New Optical Materials:

optical fibers.

Novel Electrical Conductors:

semiconductors; conducting stacks; organic conductors; superconductors; solid state ionic conductors; acentric materials; filamentary composites; conducting glasses.

\section{Materials for Extreme Conditions:}

new synthetic techniques; laser-generated surface alloys; "high-tech" ceramics.

\section{More Food}

Plant Hormones and Growth Regulators:

plant growth and rooting; induced flowering; enhanced germination; induced dormancy and fruit drop; growth inhibitors. 
Insect Hormones and Growth Regulators:

molting hormones; juvenile hormones; anti-juvenile hormones; peptide hormones/control of quiescent period; natural defense compounds; antifeedants.

Insect Pheromones

pesticides; insecticides; herbicides; fungicides; hazardous impurities.

Fixation of Nitrogen and Photosynthesis

nitrogen fixation; photosynthesis.

\section{Better Health}

Antibiotic Research

antibacterials; antifungals; antivirals.

Cardiovascular Disease

hypertension; atherosclerosis; heart failure; arhythmia.

\section{Drugs Affecting the Central Nervous System:}

antidepressants and tranquilizers; mechanism-based drug design; messenger peptides; dopamine; opiate analgesics; encephalins and selectively acting compounds.

\section{Cancer Research:}

carcinogenesis; molecular basis for cancer; chemotherapy; mutagenicity and carcinogenicity; genetic relationships

\section{Gastrointestinal Drugs:}

reduced gastric acid secretion; cimetidine and more selective agents.

\section{Inflammatory/Immunological Diseases \& Defense Systems:}

anti-inflammatory/analgesic drugs; synthetic immunogens; monoclonal antibody technologies; design of anti-inflammatory agents; understanding antibody molecules. 
Advances in Fertility control \& Fertility Induction:

orally-absorbable estrogens and progestins; fertility/restoration (clomiphene); male contraceptives (inhibin); treatment of reproductive dysfunctions.

\section{Vitamins :}

metabolic coenzymes (flavins); vitamin D - prohormone; vitamin $\mathrm{K}$ - coenzyme to allow blood clotting; complex role of vitamin $A$.

\section{Biotechnologies}

\section{Recombinant DNA Technologies:}

genetic engineering; synthesis of proteins; analytical DNA identification; separations technologies.

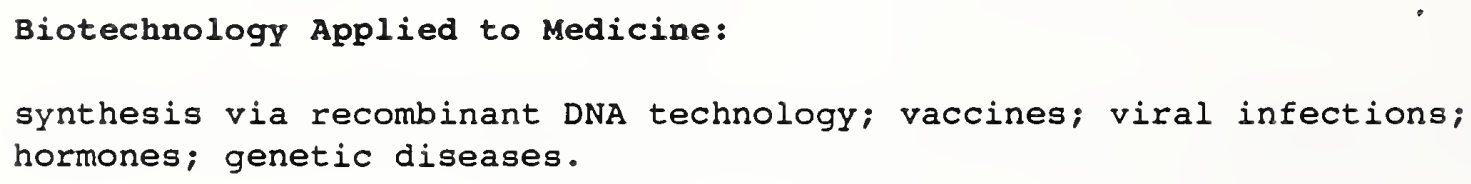

\section{Bioengineering:}

human parts replacement; blood substitutes; artificial skin and bones; genetic engineering; genetic and hormonal defects.

\section{Biocatalysis:}

rational design of synthetic enzymes; 3-dimensional structure; enzyme immobilization; lignin removal from lignocellulose.

\section{Better Environment}

Turning Detection into Protection:

toxicity threshold; risk assessment/risk management rationale; monitoring with sufficient selectivity and sensitivity; measurements of complex mixtures; remote sensing; low cost, routine monitoring; speciation research; data reduction (artificial intelligence). 
Ozone in the Stratosphere:

"odd oxygen"; man-made pollutants; nuclear winter; monitoring of trace chemicals; time evolution and variability of the stratosphere; reaction rates and product distributions.

\section{Reducing Acid Rain:}

measurements of trace species; kinetics of atmospheric reactions; role of surface organic compounds; aqueous phase photochemistry in clouds; chemistry in droplets and vapor.

\section{The Greenhouse Effect:}

biogeochemical cycle of carbon; effects of soot; residence time of aerosols; role of methane; global temperature and depletion of $\mathrm{CO}_{2}$.

\section{Cleaner Water/Safe Waste Disposal:}

subsurface migration of pollutants; advanced treatments: ozonization, wet air oxidation, plasma incineration, etc.; advanced separations: solvent extraction, microbial extraction, etc.

\section{Radioactive Waste Management:}

mechanisms for radionuclide retardation; groundwater chemistry and mineralogy; radiation and temperature effects; long-term prediction.

\section{Continued Economic Competitiveness}

\section{Energy and Feedstocks:}

petroleum depletion; petrochemical uses; coal conversion.

\section{Renewing our Industries:}

mandatory fuel economy and pollution; polymers and high performance composites; high-strength alloy steels; oil and fuel additives; corrosion prevention; reaction injection molding.

\section{New Horizons:}

biotechnology; high-technology ceramics; advanced composites and engineering plastics; photoimaging; microelectronic devices. 
Analytical Instrumentation:

improved accuracy and speed; specificity; molecular switches; molecular-scale computers.

\section{Increased National Security}

strategic and Critical Materials:

surface chemistry; synthesis and properties of new solid state materials; catalysis; separations chemistry.

\section{Surveillance and Intelligence:}

rocket plume detection; sensors; trace chemical analysis; theoretical chemistry/modeling.

Nuclear Power and Nuclear Weapons:

nuclear reactors; tritium production; actinide chemistry; laser isotope separation; radiochemical detection; processing and reprocessing.

\section{High-Speed Chemistry Explosives and Fuels:}

synthesis of new, tailored explosives; chemical kinetics of combustion; containment or treatment of hot combustion products; enhanced diagnostic techniques; modeling of turbulent combustion systems; chemical and biological agent detection and defense. 
APPENDIX D

\section{PRIORITY RECOMMENDATIONS MADE BY SURVEYS \\ OF THE NATIONAL RESEARCH COUNCIL}

$\begin{array}{ll}\text { Chemistry: } & \text { Pimentel Survey, } 1985 \\ \text { Chemical Engineering: } & \text { Amundson Survey, } 1988 \\ \text { Engineering: } & \text { Puckett Survey, } 1987 \\ \text { Physics: } & \text { Brinkman Survey, } 1986\end{array}$


Pimentel Survey

\section{Understanding Chemical Reactivity:}

Apply the full power of modern instrumental techniques and chemical theory to the clarification of factors that control the rates of reaction and to the development of new synthetic pathways for chemical change.

To provide the basis for development of new processes, new substances, and new materials.

\section{Chemical Catalysis:}

Apply the techniques of chemistry to obtain a molecular-level and coherent understanding of catalysis that encompasses heterogeneous, homogeneous, photo-, electro-, and artificial enzyme catalysis.

To develop new catalysis-aided technologies.

\section{Chemistry of Life Processes:}

Develop and apply the techniques of chemistry to the solution of molecularlevel problems in life processes and to develop young research scientists broadly competent in both chemistry and the biological sciences.

To accelerate the conversion of qualitative biological information into techniques and substances useful in biotechnologies, in human and animal medicine, and in agriculture.

\section{Chemistry Around Us:}

Understand the chemical make-up of our environment and the complex chemical processes that couple the atmosphere, oceans, earth, and biosphere, with special reference to man's conscious and inadvertent disturbance of this global reactor.

To protect our environment and to extend detection of potentially hazardous substances well below toxicity bounds so that potential problems can be anticipated and ameliorated long before hazard levels are reached.

\section{Chemical Behavior Under Extreme Conditions:}

Explore chemical reactions under conditions far removed from normal ambient conditions. Chemical behavior under extreme pressures, extreme temperatures, in gaseous "plasmas", and at temperatures near absolute zero provides critical tests of our basic understanding of chemical reactions and new routes toward discovery of new materials and new devices. 
To broaden our understanding of chemical change and to provide new materials that will have application under extreme conditions of pressure, temperature, and exposure to specially challenging environments (e.g., fusion reactors, reentry vehicle heat shields, superconducting magnets).

\section{Amundson Survey}

\section{Biotechnology and Biomedicine:}

Chemical engineering models for biological interactions; phenomena at biological surfaces and interfaces; development of process engineering including separation processes; design of bioreactors and real-time accurate and non-invasive sensors.

\section{Electronics, Photonic and Recording Materials and Devices:}

Integration of the individual chemical process steps; design and control of chemical reactors; research towards ultra-pure materials (parts per trillion level of impurity); improving chemical synthesis and processing of polymers and ceramics; deposition coating of thin films; modeling and control of the chemical process including environmental protection and safety.

\section{Microstructured Materials:}

Formation of microstructures and control of the process; fusion of materials synthesis with materials processing both in the fundamental research arena and the practical implementation; development of chemical methods to join and repair materials systems (e.g., adhesion, molecular self-assembly, etc.).

\section{In Situ Processing of Energy and Mineral Resources:}

In situ chemical reactions to extract underground resources with the earth itself as the reaction vessel; separations, combustion processes, process scaling and interactions with other disciplines such as geology, geophysics, hydrology, mineralogy, etc.

\section{Liquid Fuels for the Future:}

Chemical process pathways, processing solids, improved separations, and scale up and control of known processes.

\section{Responsible Management of Hazardous Substances:}

Long term movement of contaminants in air, water, and land, coupled with improved detection and sensing; waste degradation through biotechical means; safe responses to upset conditions, to startup and to shutdown; multispecies 
interaction and mobility of chemicals from one medium to another, e.g. from soil to water.

Advanced Computational Methods and Process Control:

Replacing laboratory and field experiments in prototyping by computer-assisted models; methodologies, databases, and complex, multiparameter, computerassisted sensors.

\section{Surface and Interfacial Engineering:}

Structure-property relations at the molecular level and improved understanding of elementary chemical and physical transformations at phase boundaries; energetics and kinetics of surface processes and the governing thermodynamics; advanced instrumentation for process control and evaluation.

\section{Puckett Survey}

Complex System Software:

Compatibility, reuse, standardization, reliability, and verification of software; use of distributed computer hardware and real-time processing of large data volumes.

\section{Advanced Engineered Materials:}

Understanding the forces between micro particles, biocompatibility, and how materials bind, deform and rupture; development of materials with prespecified properties for specific applications.

\section{Manufacturing Systems Integration:}

Modular hard and software and user-friendliness; expert systems for the design of complex manufacturing systems; complete integration of both the human and the machine components.

\section{Bioreactors:}

Large scale culture of plant and animal cells and engineered organisms; biosynthetic pathways within cells; methods for using various enzymes and catalysts for biosynthesis. 
Construction Robotics:

New design concepts, materials and methods that are adapted to the robotic functions of mobility, flexibility and high payload-to-weight ratios.

\section{Vehicle/Guideway System Integration:}

Techniques for sensing, processing and displaying data about vehicle and guideway to support communication, navigation, steering, and collision avoidance.

\section{Alternative Fuel Sources:}

Non-traditional energy source recovery or generation processes such as coal liquefaction, oil shale extraction, solar energy.

\section{Low Grade Mineral Recovery:}

Behavior of minerals during fracture, dissolution and transport; development of sensors; systems approach to mining;

in situ processing.

\section{Biomedical Engineering:}

Biomechanics, biosensors (conversion to electronics signals), biomaterials (augment body components and functions); tomography and imaging.

\section{Hazardous Material Control:}

Conversion techniques, including microbial transformations; sensors and measurement methods; supporting the ability of the environment itself to deal with contaminants.

\section{Mechanics of Slowly Deteriorating Systems:}

Long term effects of corrosion, embrittlement, and aging, including nondestructive assessment methods, and accessing the interior and microstructure of materials, structures, and parts.

\section{Computer-Aided Design of Structures:}

Three-dimensional analysis and translation of structural behavior data into physical dimensions of structural members; systems integration to link design with fabrication (the structural equivalent of manufacturing). 
Manufacturing Modeling and Simulation:

Derivation, definition and verification of computer databases; links between process variables, product characteristics and testing; robotic applications and integration including image processing, collision avoidance, and reaction to faults.

\section{Electronics Device and Packaging Technology:}

Bi-polar silicon logic; fabrication methods for submicrometer structures; three-dimensional device and circuit technology; magnetic and optical storage devices and their process technologies.

\section{Brinkman Survey}

Note: No priority areas for research are given in the Brinkman Survey. The following is a listing of areas mentioned in the two fields of physics most relevant to NIST activities: (1) Atomic, Molecular and Optical Physics, and (2) Condensed Matter Physics.

\section{(1) Atomic, Molecular and Optical Physics}

\section{Fundamental Tests and High Precision Techniques:}

Elementary structure; QED in highly charged systems; laser spectroscopy of exotic atoms; trapped electrons, ions and atoms.

\section{The Many-Electron Atom:}

Inner shell spectroscopy; spectroscopy of highly charged ions; multiphoton processes; highly excited atoms.

\section{Transient States of Atomic Systems:}

Particle beam collision measurements; collisions in laser light; quantitative collision theory.

\section{Physics of Isolated Molecules:}

Transient molecular species; clusters; chaos; reactive plasmas; excited state dynamics; XUV and $\mathrm{X}$-ray photoionization.

Physics of Molecular Collisions:

state-to-state chemistry; collisions in laser light; half-collisions; special molecules. 
New Light Sources:

Short-wavelength lasers; non-linear processes; short pulses; new lasers.

\section{Advanced spectroscopy:}

Ultraprecise spectroscopy; doppler-free spectroscopy; ultra-sensitive detection.

\section{Quantum Optics:}

Preparation of light in novel statistical states; optical bistability; electrodynamics at long wavelengths.

\section{(2) Condensed Matter Physics}

\section{Surfaces:}

Structures and excitations; solid-solid interface; solid-liquid interface; scanning tunneling microscopy; ion backscattering; grazing incidence X-ray scattering; low-energy electron diffraction; electron energy loss spectra; atomic diffraction.

\section{Glasses \& Amorphous Materials:}

Disordered materials/chaos; magnetic; non-magnetic; polymer glasses.

\section{Artificially structured Materials:}

Artificial superlattices; microscopic order; interface states; transport mechanisms.

\section{New Crystalline Materials:}

High $T_{C}$ superconductors; heavy fermion conductors; charge density wave materials.

\section{Phase Transitions:}

Kinetics. 
Femtosecond Laser Spectroscopy:

Phase transitions; surface chemistry; electronic properties; structural changes.

Free Electron Laser and Synchrotron Radiation:

Non-linear optics; crystal defects; small sample studies; electronic structure.

Neutrons :

Excitation above thermal energies; high frequency vibrations. 


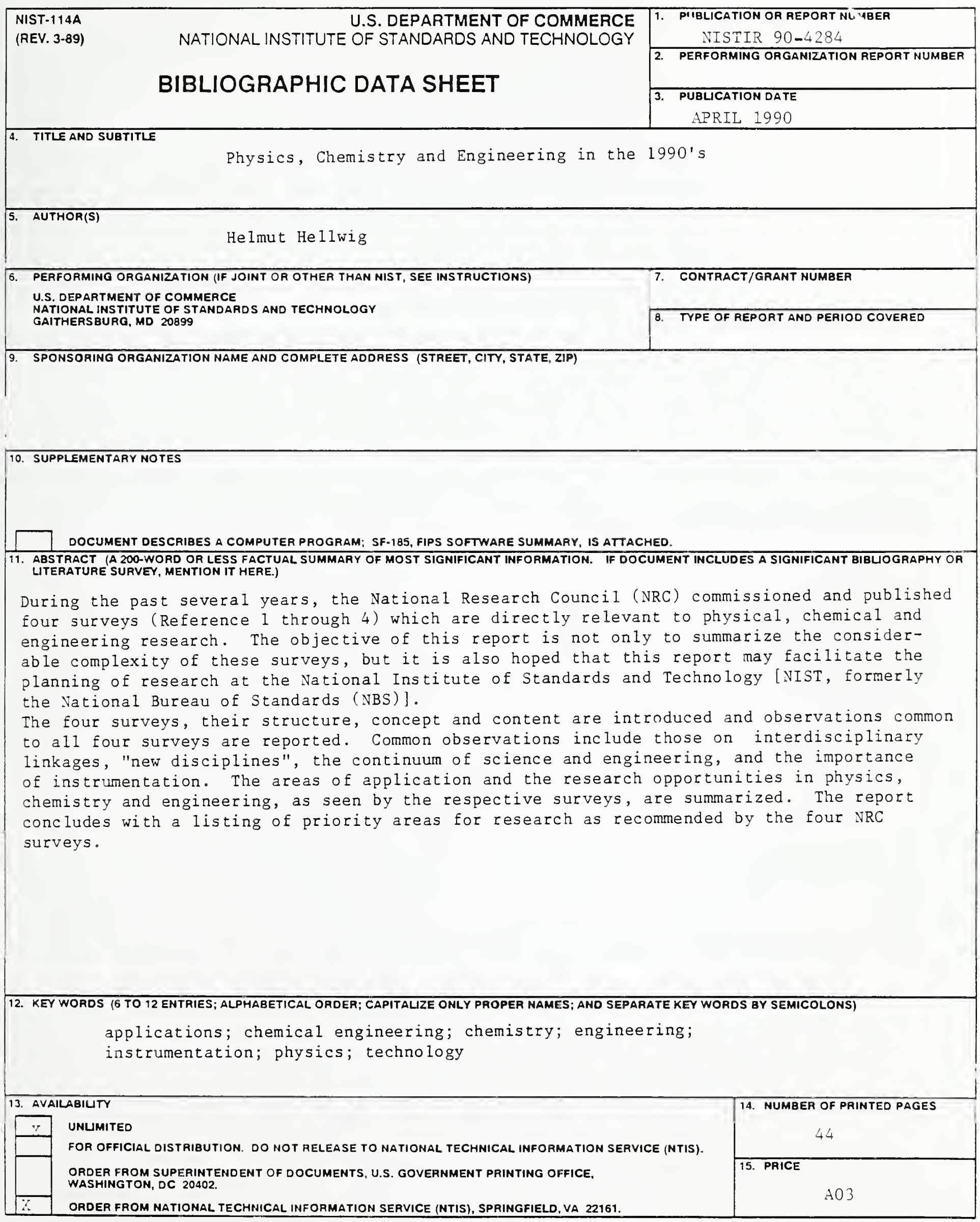



